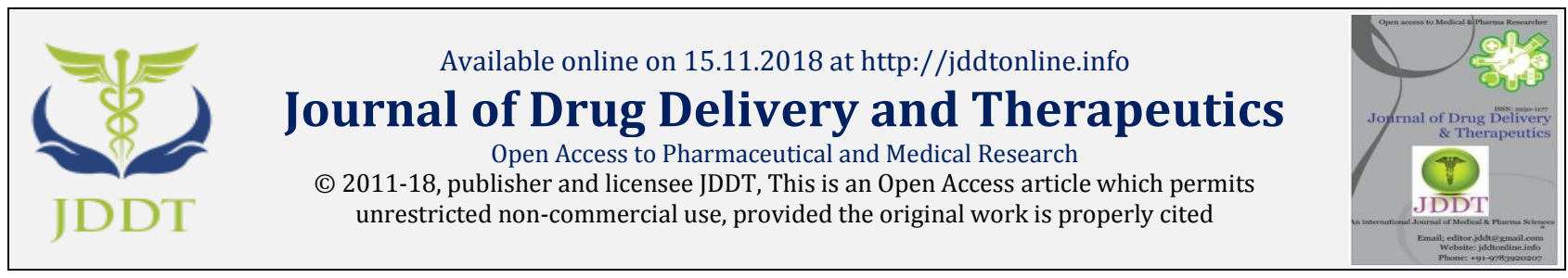

Open $\odot$ Access

Review Article

\title{
An updated review on Anti-Alzheimer's herbal drugs
}

\author{
Nihitha Sanka*, N. Santhipriya, Rama Rao Nadendla. \\ Department of Pharmaceutics, Chalapathi institute of Pharmaceutical sciences, Lam, Guntur, India
}

\begin{abstract}
Alzheimer's disease (AD) is related to cognitive impairment, dementia observed generally in aged population due to neurodegeneration in an ongoing manner. It gradually worsens memory power of the patient. The hallmark diagnosis features includes formation of senile plaques and Neurofibrillary tangles (NFT'S). Too little availability of Acetyl choline (ACh) a neurotransmitter in the cerebral region due to metabolism by an enzyme Acetyl choline esterase before showing its action and neural death are the primary reasons for AD. There are many categories of Anti-Alzheimer's drugs available for management of AD in the market but due to lack of patient compliance successful outcomes were not observed. Apart from this including Nutraceuticals in diet daily routine, Aromatherapy, modifications in the regular schedule, practicing yoga regularly relaxes mind and body from tensions, insomnia, blood circulation, detoxification of organs due to rhythmic breathings and reduce frequency of incidence of headache are proven to show best results by relieving stress according to survey. At present herbal medicine has turn out to be best choice for the management of AD because of its availability, very economic, good patient compliance, ease of formulation and lower deleterious side effects. Novel techniques can be used for the development of herbal medicine. This review totally discuses about the occurrence of AD, its Pathophysiology, different stages in the disorder, various selective therapeutic targets for AD, available Anti$\mathrm{AD}$ herbal drugs such as Curcumin, Withania somnifera, Bhrami, Ginkgo biloba, guggul, ginseng, herbs with essential oils, volatile oils, source and cultivation of the herbs, mechanism of action of the Phytochemicals in the herb responsible for treating AD.
\end{abstract}

Keywords: Alzheimer's disease (AD), cognitive impairment, Dementia, Senile plaques, Nutraceuticals, Herbal medicine, Phytoconstituents.

Article Info: Received 03 Oct, 2018; Review Completed 09 Nov 2018; Accepted 09 Nov 2018; Available online 15 Nov 2018

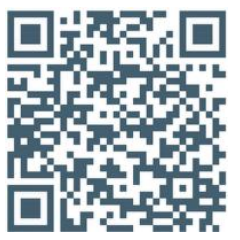

Cite this article as:

Sanka N, Santhipriya N, Nadendla RR, An updated review on Anti-Alzheimer's herbal drugs , Journal of Drug Delivery and Therapeutics. 2018; 8(6):360-372 DOI: http://dx.doi.org/10.22270/jddt.v8i6.2049

*Address for Correspondence:

Nihitha sanka, Department of Pharmaceutics, Chalapathi institute of Pharmaceutical sciences, Lam, Guntur, India

\section{INTRODUCTION 1,12}

Alzheimer's is a neurodegenerative disorder caused due to cognitive impairment and Dementia. Alzheimer's disease International (ADI) is the international federation of Alzheimer associations around the world, in official relations with the World Health Organization believes that the key to winning the fight against dementia lies in a unique combination of Global Solutions and local knowledge. World Alzheimer's Month, celebrated each September, with World Alzheimer's Day on September 21, is an opportunity to raise global awareness about dementia and its impact on families and the important work of our members throughout the world. Alzheimer's \& Related Disorders Society of India in Kerala is the Indian association that compiles all the issues related to AD. Numerous strategies, drugs, herbal medicines and various drug delivery systems exist for AD but they don't assure permanent cure for it, usage of herbal medicine along with a suitable drug delivery system as a remedy for $\mathrm{AD}$ is the best choice when compared to Allopathic medicine as they overcome the unwanted side effects and improves patient compliance.

\section{ALZHEIMER'S DISEASE 1,2,13,14}

In 1906 Dr. Alois Alzheimer upon his scrutiny identified brain of a woman who lost her life due to some unusual symptoms such as loss of memory, unpredictable behavior, cognitive impairment he then conclude the death was due the presence of neuritic plaques and neuro fibrillary tangles and named the disease as ALZHEIMERS DISEASE. It has been developed into a predominant nerurodegerative disease in the elderly population. A component of healthy nerve cells, Amyloid precursor protein derivative $\beta$ Amyloid protein deteriorates and lead to the formation of Neutric plaques, they are also called as senile, dendritic or amyloid plaques. Nerve cells along with various other components it consists of twisted protein fibers positioned within nerve cells. These fibers consist of a protein, called tau, which normally occurs in neurons. When incorrectly processed, tau molecules clump together to form Neuro fibrillary tangles. This disease may be in some way 
interrelated to brain infection, plaque formation being one or the other excessive in older individuals or abnormal in some other way in persons who ultimately develop Alzheimer disease

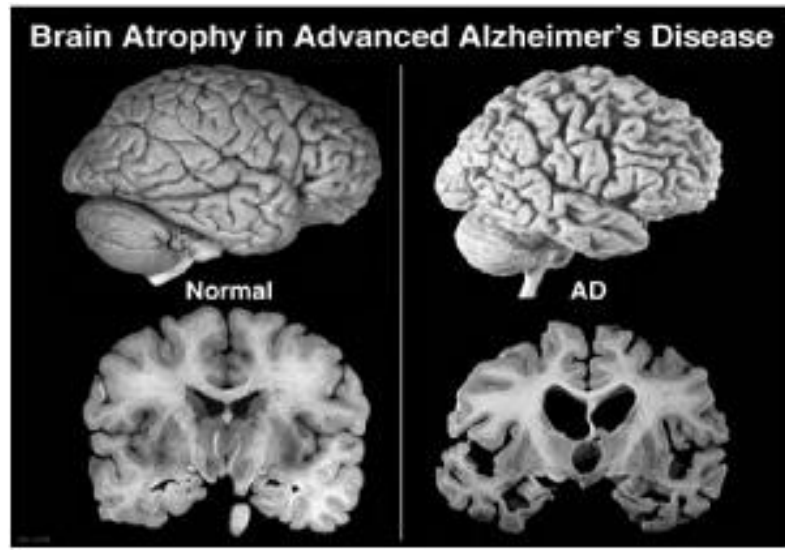

Figure 1: Difference between normal and AD affected brain 15

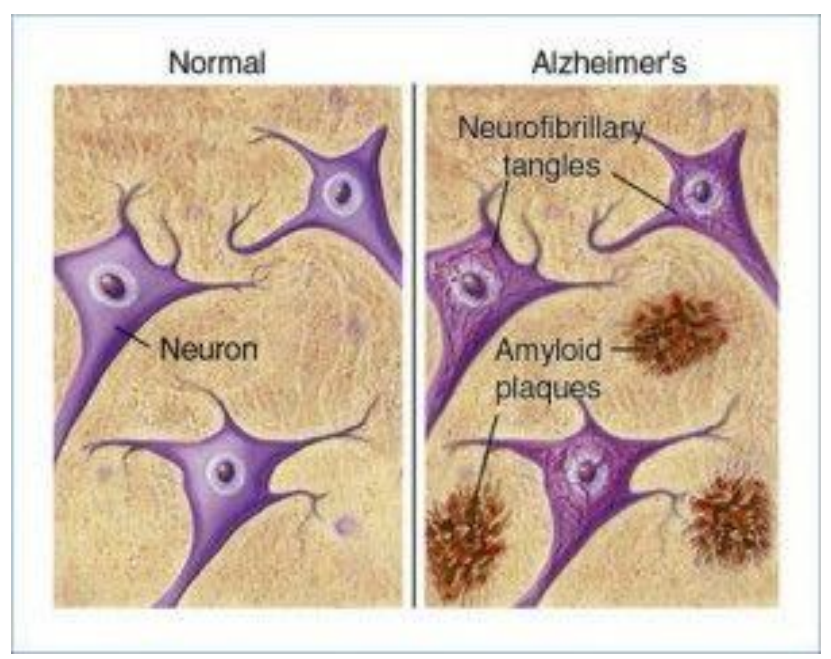

Figure 2: Formation of senile plaques and NFT'S 16
Warning signs for AD are: 2, 3,11, 13, 17

- Memory loss that affects day-to-day abilities. Difficulty performing familiar tasks

- $\quad$ Problems with language

- Disorientation in time and space.

- Problems with abstract thinking.

- Misplacing things.

- Changes in mood and behaviour.

- Loss of initiative

In general, population think these signs are part of usual aging, it's not true. Upon observation of these symptoms or changes in capabilities or behavior, they must consult a doctor. Reasons for These changes include depression, drug interactions or an infection. On diagnosis of Alzheimer's disease in early stage it is possible to get proper treatment, information and support regarding the disease.

\section{PATHOPHISIOLOGY OF THE DISEASE: 14, 18}

Senile plaques (SPs) and Neuro fibrillary tangles (NFTs) are considered the key pathological hallmarks of AD. Numerous hypotheses have been put forward on the basis of the various causative factors in order to explain this multifactorial disorder. Some of them included are:

- cholinergic hypothesis

- Amyloid beta hypothesis

- Tau hypothesis

- Inflammation hypothesis

In recent times it has been shown that the most commonly used Amyloid beta hypotheses, prevailing for the last two decades, does not relate to the complex Pathophysiology of this draining disease. Amyloid beta oligomers in synaptic injury, suggesting that these are first and foremost among several other signals that destroy the reliability of brain functions. Amyloid plaques formation are develop in the later age, these Amyloid beta oligomers leads to cognitive impairment due neurotoxicity.

Amyloid Cascade hypothesis and Cholinergic hypothesis these two has detailed the mechanism of occurrence of AD.

Amyloid cascade hypothesis:

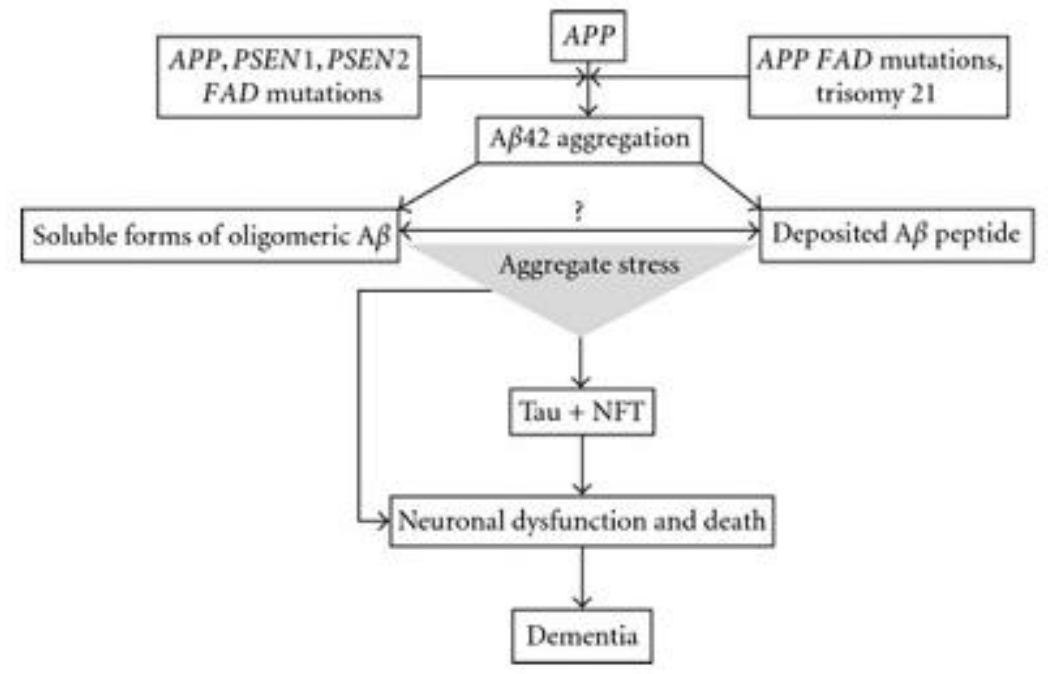

Neuro fibrillary tangles (NFTs),Beta-amyloid (A $\beta$ ), Amyloid precursor protein (APP), Presenilin 1 (PSEN1), and Presenilin 2 (PSEN2) genes

Figure 3: Amyloid cascade hypothesis 19 


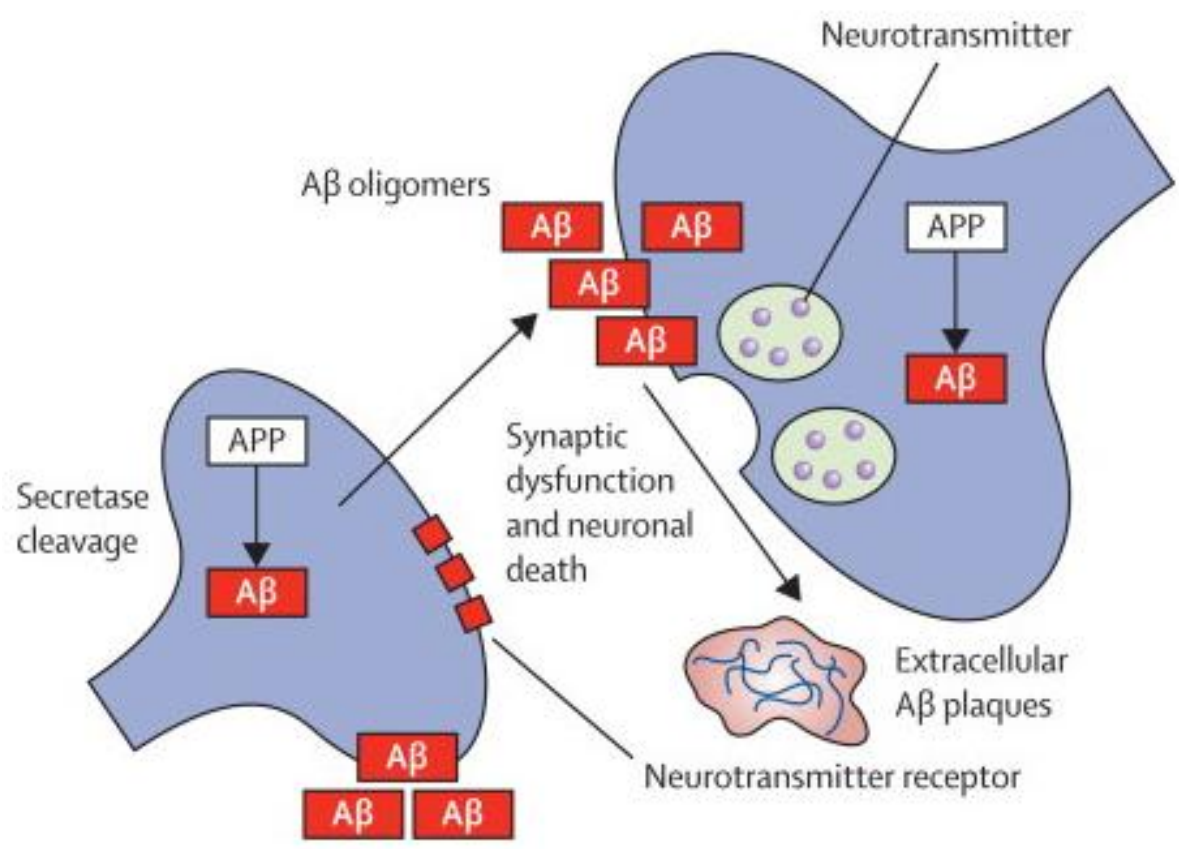

Figure 4: Amyloid $\beta$ plaques formation 20

\section{CHOLINERGIC HYPOTHESIS}

Wide spread cell dysfunction \& degeneration will lead to neurotransmission defects majorly effected is cholinergic neurons. Loss of cholinergic activity is corrected with $\mathrm{AD}$ severity as the disease progresses the cholinergic neurons starts to deplete along with these nicotine receptors in the hippocampus region and cortex are also reduced but the presynaptic nicotine receptors control the release of acetyl choline. By this hypothesis it is concluded that this is the reason for cognitive impairment in $\mathrm{AD}$, Reversal or treatment of $\mathrm{AD}$ is not possible upon addition of Acetyl choline.
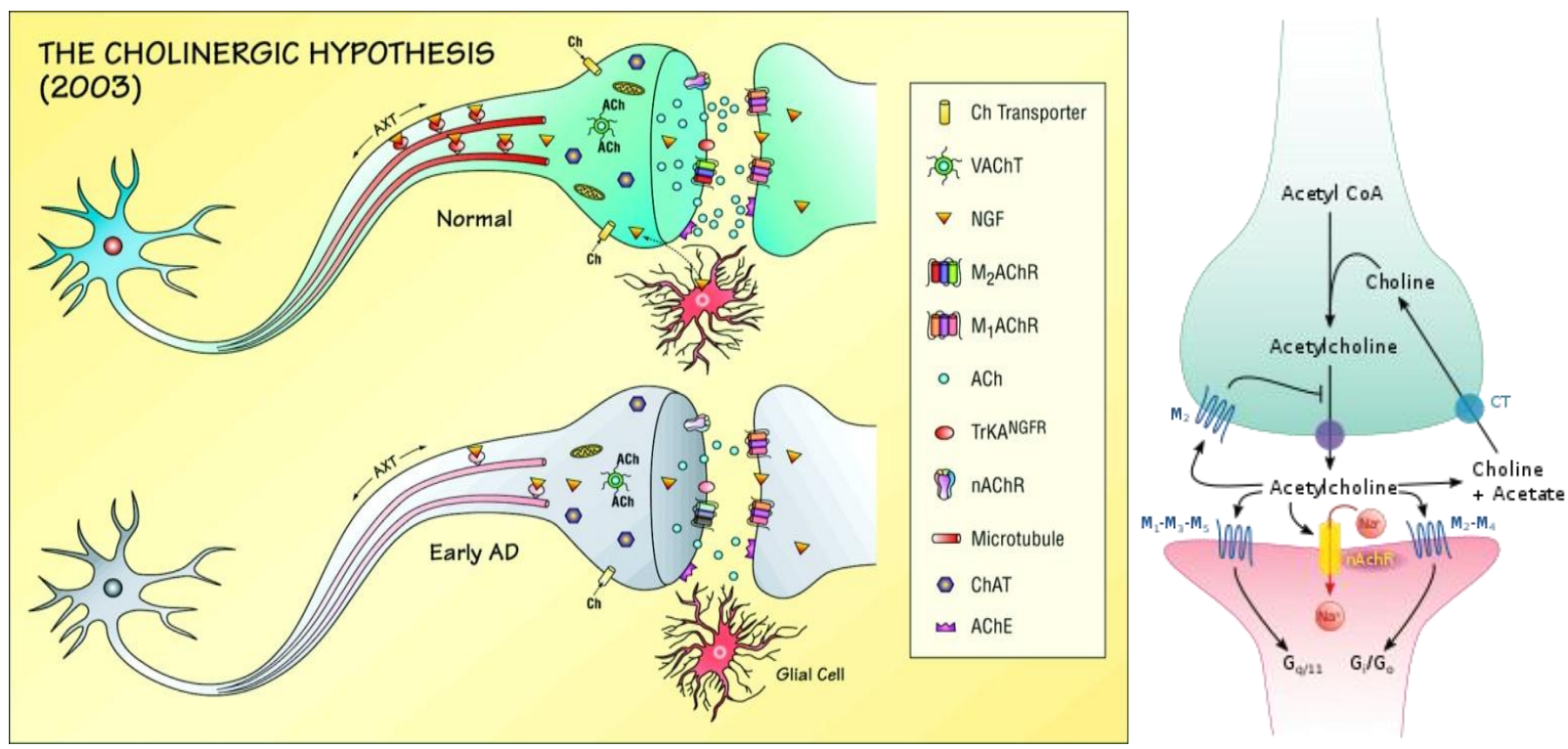

Figure 5: cholinergic hypothesis ${ }^{21}$ 
Stages in: 11, 12, 22, 23

\section{Mild AD}

-Person may function independently in the early stage.

- They can do their social activities.

- person may feel as if they are suffering from memory lapses, such as disremembering commonly used words or the location of ordinary objects.

- Common difficulties faced by them are Problems coming up with the right word or name,be unable to remember material that one has just read, Misplacing a valuable object.

\section{Moderate AD}

- Greater care is needed to the patient As the disease progresses.

- It is classically the longest stage and can last for many years,.

- Individuals may have greater difficulty performing tasks

- Confusing words, getting frustrated or angry, or acting in unexpected ways

- symptoms include:

- Forgetfulness of events or about one's own personal history

- Feeling moody or withdrawn, especially in socially or mentally challenging situations

- Confusion about where they are or what day it is.

\section{VARIOUS THERAPEUTIC TARGETS TO TREAT AD: 24}

- Targeting Amyloid beta protein (Anti-Amyloid approach )

- $\quad$ Targeting Amyloid transport

- Modulation of Secretase enzyme

- Targeting amyloid clearance

- Amyloid based vaccination therapy

- $\quad$ Targeting Tau protein

- Neurogenesis.

\section{Medicinal plants used in the treatment of AD:11,23,25-27}

Present day therapies are insufficient and have enormous adverse effects. So there is an urgent need for possible alternative treatments for AD with minimal or no side effects. Various medicinal plants are suggested to enhance the memory and treat AD. Herbal therapy for AD has more advantages when compared to currently existing drug therapies with unavoidable side effects it can also improve the patients' quality of life as they can be consumed as Nutraceuticals and even any slight increase in dose may not be a problem when consumed. In order to deliver these herbal formulations a proper route of administration must be selected so that they reach the site and show the therapeutic action

\begin{tabular}{|l|l|l|}
\hline Herb name & $\begin{array}{l}\text { Family\& Common } \\
\text { name }\end{array}$ & \multicolumn{1}{c|}{ Uses } \\
\hline Curcuma longa & $\begin{array}{l}\text { Zingiberaceae } \\
\text { Turmeric }\end{array}$ & $\begin{array}{l}\text { Anti inflammatory } \\
\text { Increases Anti oxidant capacity of body } \\
\text { Lowers the risk of heart diseases } \\
\text { Prevents cancer } \\
\text { Preventing and treating AD } \\
\text { Delays aging and fights age related chronic diseases }\end{array}$ \\
\hline Withania somnifera & $\begin{array}{l}\text { Solanaceae. } \\
\text { Ashwagandha }\end{array}$ & $\begin{array}{l}\text { To treat cancer } \\
\text { As Immunostimulants } \\
\text { Increases libido and sexual function } \\
\text { As free radical and anti oxidant } \\
\text { For anxiety and depression }\end{array}$ \\
\hline
\end{tabular}




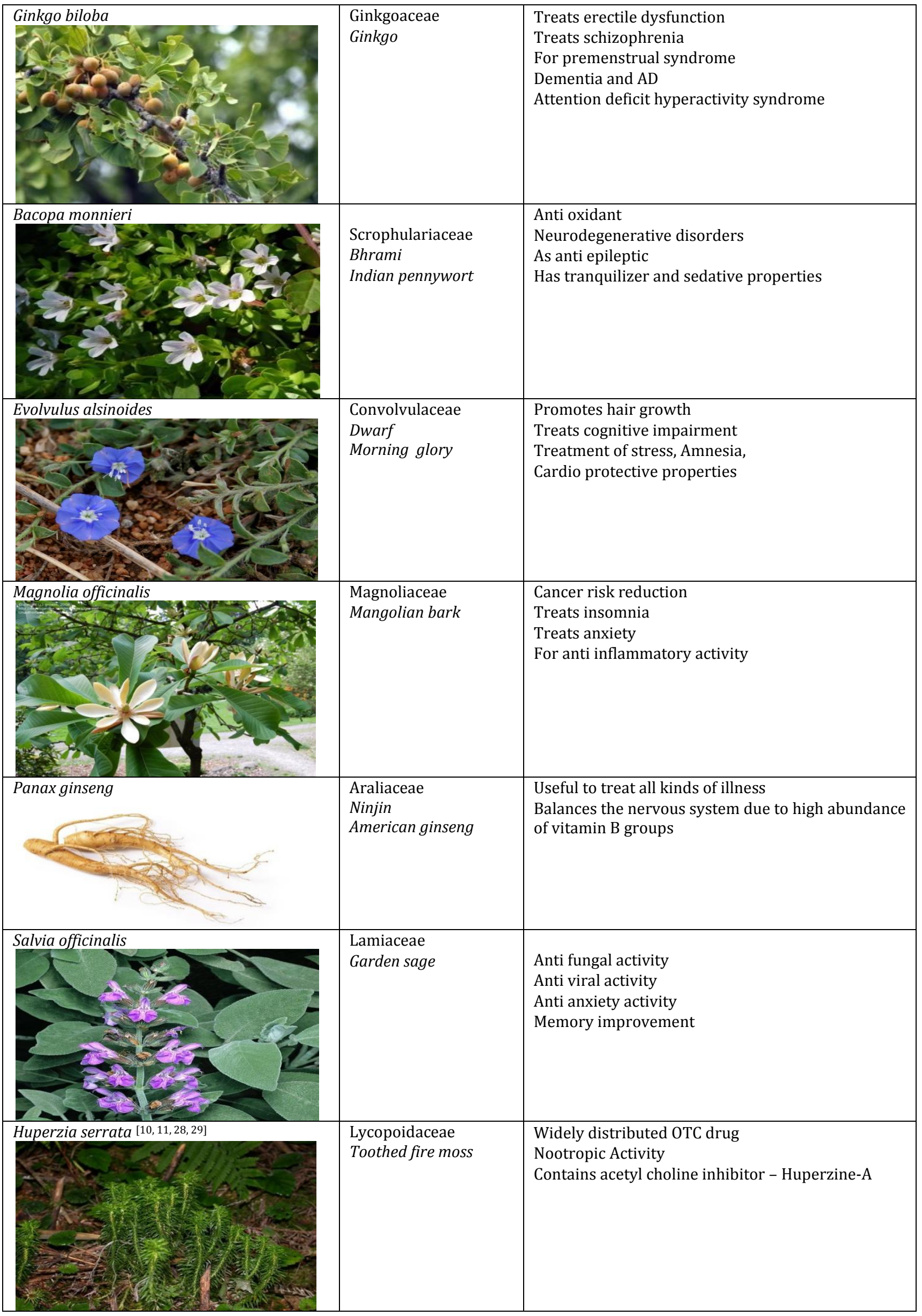




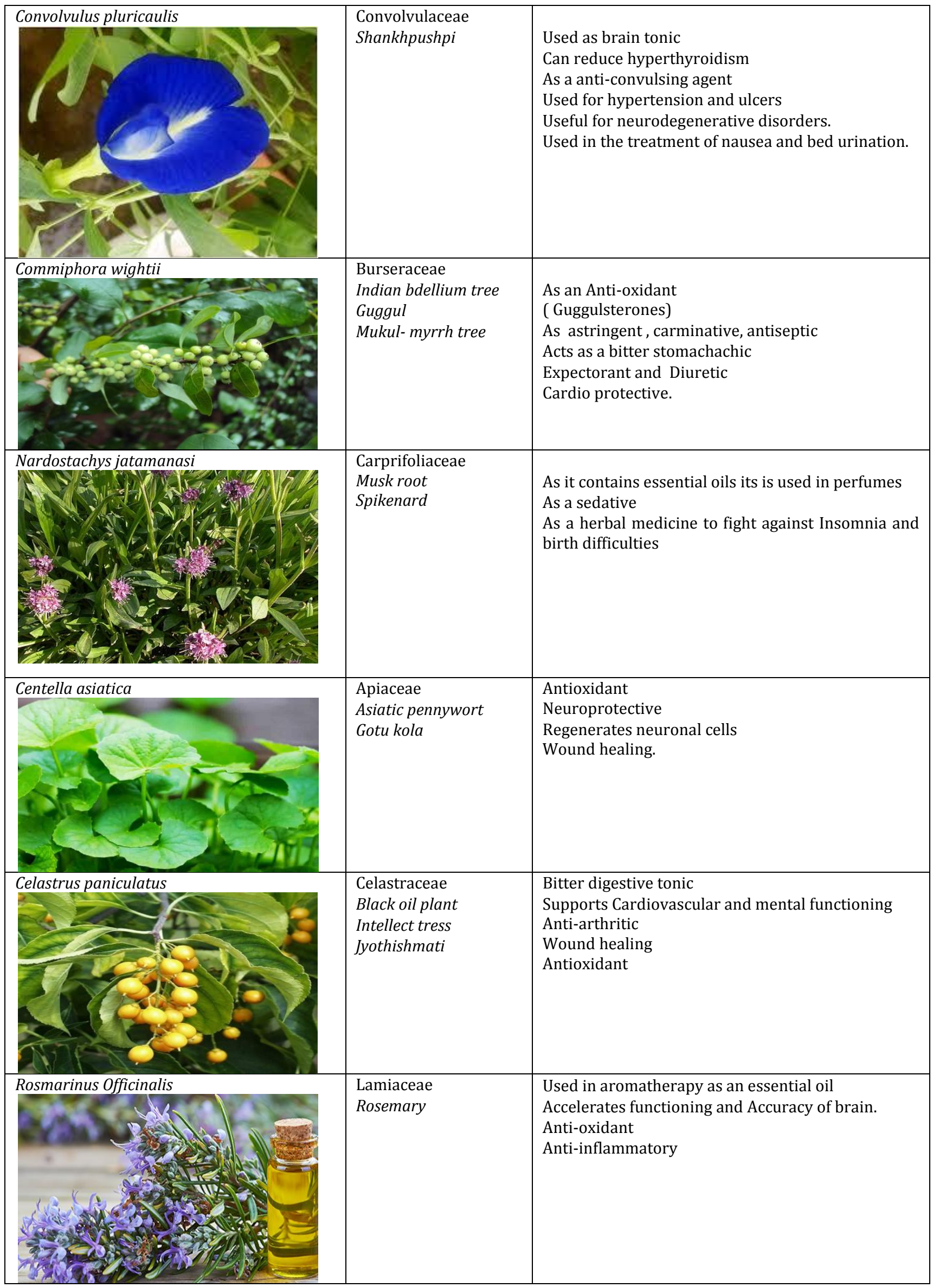




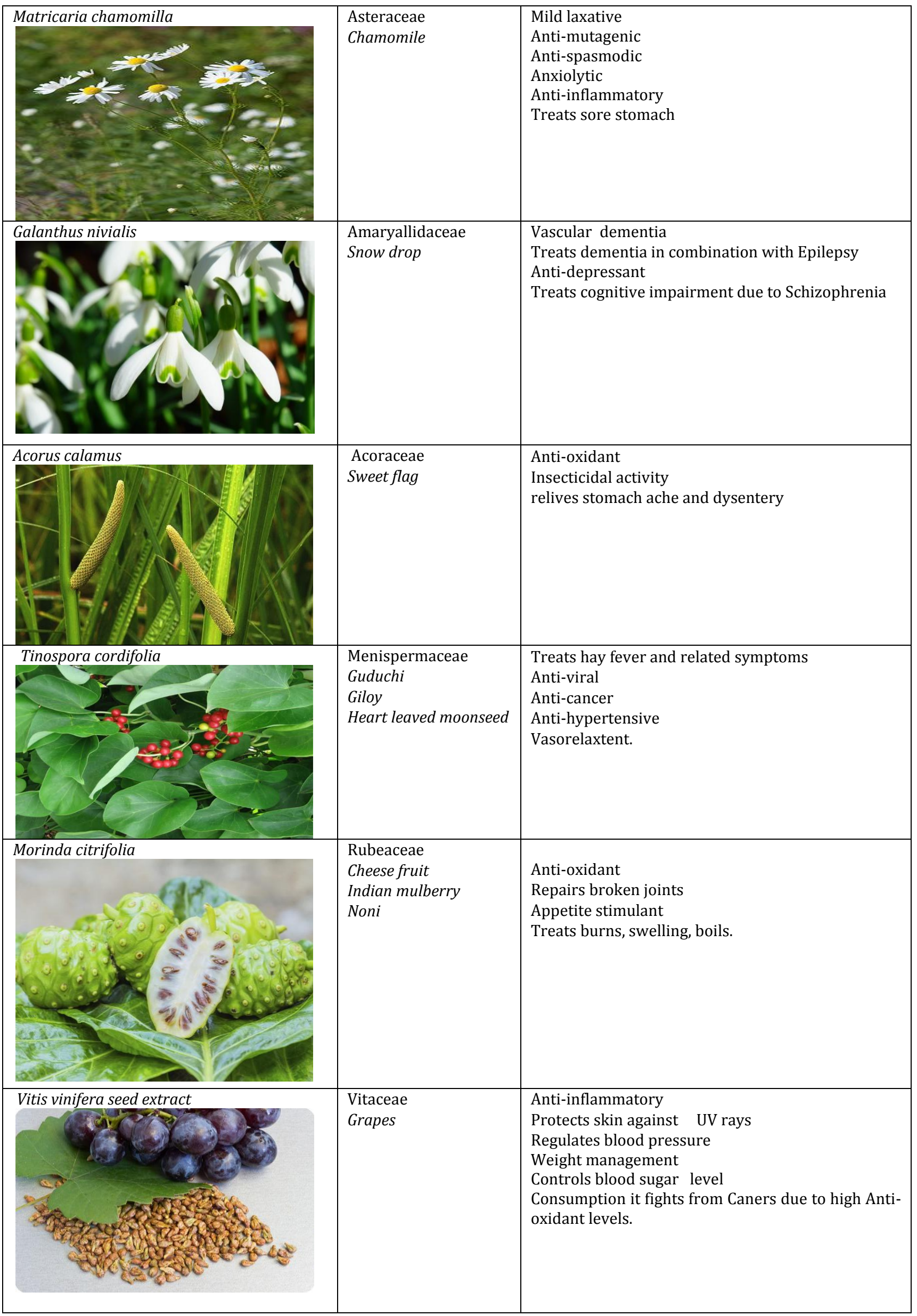




\begin{tabular}{|l|l|l|}
\hline Melissa officinalis & $\begin{array}{l}\text { Laminaceae } \\
\text { Lemon balm } \\
\text { Balm mint }\end{array}$ & $\begin{array}{l}\text { Treats disorders related to liver, bile, nervous and } \\
\text { gastrointestinal system. } \\
\text { Aromatherapy }\end{array}$ \\
\hline Utrica dioica & $\begin{array}{l}\text { Utricaceae } \\
\text { Common nettle } \\
\text { Stinging nettle }\end{array}$ & $\begin{array}{l}\text { Anti- inflammatory } \\
\text { Anti-oxidant } \\
\text { Wound healing } \\
\text { Factures } \\
\text { Analgesic } \\
\text { haematuria }\end{array}$ \\
\hline
\end{tabular}

\section{PHYTOCHEMICAL SCREENING AND MECHANISM OF ACTION 22, 28, 30-32.}

Phytochemicals are the chemical molecules contained in plants not usually processed for pharmacological purposes. Phytochemicals influence the function of various receptors for both excitatory and inhibitory neurotransmitters in the brain and thus can maintain or alter the chemical balance of the brain.

\section{Curcuma longa :}

It is commonly called as turmeric used in Asia for thousands of years in Ayurveda, Siddha, Unani, traditional Chinese medicine. The world's largest producer, consumer and exporter of turmeric is India. It is a perennial herbaceous plant. The turmeric powder contains $60-70 \%$ carbohydrates, $6-13 \%$ water, $6-8 \%$ proteins, $3-7 \%$ essential oils, $2-7 \%$ dietary fiber, $1-6 \%$ curcuminoids. It has been proven that curcumin usage is useful in the treatment of $\mathrm{AD}$ and dementia it also has the ability to decrease the formation of Amyloid plaques and delays degradation of neurons as these both are hallmark of $\mathrm{AD}$ the overall memory of $\mathrm{AD}$ patients is improved Curcuminoids are proven to have strong antioxidant action demonstrated by the inhibition of the formation and propagation of free radicals. It decreases the low-density lipoprotein oxidation and the free radicals that cause the deterioration of neurons, not only in AD but also in other neuron degenerative disorders such as Huntington's and Parkinson's disease. The levels of beta-Amyloid in AD mice that were given low doses of curcumin were decreased by around $40 \%$ in comparison to those that were not treated with curcumin. In addition, low doses of curcumin also caused a $43 \%$ decrease in the so-called "plaque burden" that these beta-Amyloid have on the brains of $\mathrm{AD}$ mice. Surprisingly low doses of curcumin given over longer period were actually more effective than high doses in combating the neurodegenerative process of $\mathrm{AD}$, at higher concentration, curcumin binds to Amyloid beta and block its self assembly 10,33 .

\section{Withania somnifera : 34}

This plant is commonly called as Ashwagandha or Indian ginseng; it contains different types of chemical constituents such as alkaloids, steroidal lactones, saponins. Anciently it has been used as medicinal plant in Ayurveda as it posses multiple uses. The bioactive component and the plants extract are used in treatment and prevention of various diseases such as Arthritis, impotence, amnesia, cancer and neurodegenerative disorders. It has capability to revitalize nerves, bone marrow and reproductive system property. Ashwagandha can improve cognitive behavior in rats subjected to oxidative damage that occurs in $\mathrm{AD}$ and can reverse accumulation of $\beta$-Amyloid peptides (A $\beta)$ implicated in the disease. Researches stated that Withania somnifera produces its beneficial effects by reducing oxidative damage, enhancing toxic $A \beta$ clearance and can attenuate neurodegeneration. The mechanism of action of Withania somnifera in humans is not clear. Animal studies have shown that the Sitoindosides VII-X and WithaferinA A (glycowithanolides) are the active phytophenols, responsible for the mechanism of increased cortical Muscarnic acetylcholine capacity, with a modulation of cholinergic neurotransmission. These studies indicate the use of Withania somnifera can cause significant changes in neurological baseline functions. Molecular modeling studies showed that Withanamides-A, C Uniquely bind to active moiety of beta-amyloid and prevent fibril formation. Aqueous extract increases the cholinergic activity, whereas Methanol extract causes neuritis outgrowth in dose and time dependent manner in human neuroblastoma cells. Researchers postulate that it can be applied clinically in prevention, and possibly repair, of central nervous system disorders.

\section{Bacopa monnieri: 35}

Bacopamonniera (Bhrami) in the Ayurveda system of Indian Herbal Medicine has been used for centuries. Traditionally, Ayurvedic medical system has been using it for anxiety relief, as a tonic for the brain to enhance learning and memory development, and prevention of epilepsy. Aging leads to various degenerative changes in the body, and the quantity and quality of these changes depend on upon the anatomy and physiology of the tissue. The factors that contribute to these changes are oxidative damage to the DNA and hormonal deficiency. Normal stress response requires synchronized functioning of various hormones and neurotransmitters. Bacopa contains many alkaloids, such Asbrahmine and Herpestine, saponins, d-mannitol, Hersaponin and monnierin that are responsible for the medicinal value. Other active constituents include betulic acid, Stigmastarol, beta- 
sitosterol, numerous bacosides, and bacopasaponins. The bacosides enhance kinase activity, neuronal synthesis, and restore synaptic activity. These neuronal repair actions are valuable in $\mathrm{AD}$ management. In hippocampus it enhances protein kinase activity that may contribute to its nootropic activity which means an improvement in cognitive functioning. Bhrami extracts have show protection of neurons from beta- Amyloid induced cell death by suppressing cellular acetyl cholinesterase activity. It has also reversed actions such as depletion of acetyl choline, reduction in Choline acetyl Transferases, decrease in Muscarnic cholinergic receptor binding in frontal cortex and hippocampus.

\section{Ginkgo biloba :}

It is commonly called as ginkgo the only species in the species ginkophyta this plant is native to china and south Japan; it has several uses in traditional medicines and as a source of food. Extracts of ginkgo leaves contain different types of phytochemicals they include phenolic acid, proanthocyanidins, flavonoid glycosides (Myricetin, kaempferol, isohamnetin, quercerin), Terpens, ginkolides, biobalides, ginkgo biflavones as well as alkylphenols. The flavonoids and Terpens in the extract significantly inhibit acetylcholinesterase activity in brain. Ginkolides are the chief chemical constituents it is a potent anti-oxidant with cholinergic and neuroprotective activities hence it protects against $\mathrm{A} \beta$-Protein induced oxidative damage. It shows several molecular and cellular neuroprotective mechanisms including attenuation of apoptosis, inhibition of membrane lipid peroxidation, anti-inflammatory effects and direct inhibition of Amyloid beta aggregation

\section{Evolvucus alsinoides: 36}

It is a flowering plant commonly called as slender dwarf morning glory. It has a natural Pantropical distribution in tropical and temporate regions such as America, Africa, Australia, and Indomalasia. Evolvucus alsinoides is included as one of the ten sacred flowers in Kerala (Dasapushpam). In East Asia it is used as a traditional medicine due to its psychotropic and nootropic activities. Phytochemicals in this plant includes Scopoletin, scopolin, umbelliferone, 2-methyl-1,2,3,4-butanetertrol.

\section{Convolvulus pluricaulis : 10}

The common name of this species is shankhpushpi found in India and Burma mostly used in ayurvedic medicine. Whole plant contains phytochemicals such as Glycosides, Coumarines, flavonoids, Alkaloids (Shankhpushpi) other constituents include Sitosterol, Hydroxy cinnamic acid, Octacosanol, Tetracosane along with glucose. Since ages it has been used as brain tonic, tranquilizer and phytostimulent. It is finest and best tonic for improving memory and used in the treatment of dementia, OCD, phobias, Insomnia. It calms the nerves by regulating stress hormones, Adrenaline and cortisol. Ethanolic extract, ethyl extract of it and aqueous fraction significantly improved learning and memory in rats. Hippocampus region of brain associated with learning and memory functions has showed a dose dependent increase in acetyl cholinesterase activity when treated with it.

\section{Panax ginseng: 10,37}

It is the root of the plant Panax. Widely it is cultivated in various varieties such as Korean ginseng, south china ginseng, and American ginseng. Phytoconstituents of this plant include polysaccharides, Ginsenosides, peptides, Polyacetylenic alcohols, fatty acids, it also contains saponins - Protopanaxadiaol, Protopantrol, Oleanolic acid they are been reported to have memory-enhancing action for learning impairment induced by scopolamine .Ginseng is able to enhance the psychomotor and cognitive performance and benefit $\mathrm{AD}$ by improving the brain Cholinergic function, reducing the level of $\mathrm{AD}$ and repairing the damaged neuronal network.

\section{Commiphora wightii : 10,38}

It is commonly called as guggul found in northern Africa to central Asia, this plants grows abundantly in arid and semiarid climates and tolerates poor soil. Effectively used in Unani and ayurvedic medicine. Gum guggul extract contains various phytochemicals such as Diterpenoids, triterpenoids, steroids, long chain aliphatic tetrols, carbohydrates, volatile oils, lignans, and Amino acids. It has significant protective effect against the Streptozotocininduced memory deficit model of dementia and the effect can be attributed to its cholesterol lowering anti-oxidant and anti-acetylcholinesterase activity these observations suggest Guggulipid as a potential Anti-dementia drug. It acts on impairment in learning and memory and decreased acetylcholinesterase levels in hippocampus.

\section{Magnolia officinalis : ${ }^{39}$}

It is commonly called as Houpa magnolia they Are distributed widely in mountains and valleys of china at higher altitudes. The whole bark contains phytochemicals such as Magnolol, Honokiol, Two Polyphenolic compounds. This plant shows peroxisome-proliferator activated receptor gamma agonistic activity (PPAR Gamma) and acts as GABA modulator. It is potentially used as Anti-oxidant, Anti-inflammatory, Anti-microbial properties. Oral pretreatment of two extract products of Magnolia officinalis $(10 \mathrm{mg} / \mathrm{Kg} /$ Day in ethanol) into drinking water for 3 months ameliorated memorial dysfunction and prevented Amyloid beta accumulation in the brain. The extracts also also showed a decrease in amyloid precursor proteins and its products. Hence it is effective in treatment and prevention of $\mathrm{AD}$ through memory Enhancement antiamyloidogenic effects through down regulation of $\beta$ Secretase activity and the extent of neuroprotective efficacy depends on area where it is cultivated and methods followed during manufacturing.

\section{Nardostachys jatamanasi (Jatamansi): 10}

It is a flowering plant commonly called as muskroot or spikenard cultivated throughout Nepal, Sikkim, and Bhutan. This plant has intense aromatic amber coloured essential oils hence it is used in perfume preparations. Chemical constituents of this plant includes Acaclin, Ursolic acid, Octacosanol, Nardosinonediol, Oleanolic acid, $\beta$ Sitosterol. When alcoholic extract of this plant are given to young and aged rats they have show significantly improved learning and memory and also reversed the Amnesia induced by Diazepam and Scopolamine. It has also reversed aging induced amnesia due to natural aging of mice suggesting that the compound in this plant may prove to be useful in restoring memory in older individuals as well as in patients with age-associated dementia

\section{Centella asiatica: $40-48$}

It is a perennial flowering plant native to Asia used as culinary vegetable Cognitive enhancer and medicinal herb. It contains various chemical constituents such as Pentacyclic triterpinoids, Centellose, Centelloside, Madecassoside and Asiaticoside derivatives which include Asiatic acid and Asiaticaside they have shown to reduce Hydrogen peroxide induced cell death, decreases free radical concentrations and inhibit $\beta$-Amyloid cell death. 
Water extract of this plant has shown mitigation of $A \beta$ induced cell death and also it has attenuated $A \beta$-induced alternations in Tau expression and phosphorylation in cell lines (according to Gray nora. et.al,). It has the ability to reduce Oxidative stress, prevents shrinkage of neuronal process (according to a survey by Alzheimer's Drug Discovery Foundation). Extracts of this plant reduces lipid peroxidation and protects DNA against damage (according to Dhanasekaran M. et. al,). This plant is essential for brain and nerve cells and it's capable of enhancing intellect and logetivity.

\section{Celastress panicultus: ${ }^{10,49-53}$}

It is a climbing shrub grows throughout India used as traditional medicine in Unani and Ayurveda. This plant sharpens the memory and its seed posse's cholinergic activity. It improves medhya-guna which means improved memory power to serve this purpose almond, Cardamom, Jatamanasi, Shankhpushpi are used along with it. Phytochemicals in the stem portion are alkaloids they include Winfornine F, Paniculatine A and B, where as the seed portion contains Celastrine, Celapagine, Celpanigine, Celapanine. These extracts protect neuronal cells against hydrogen peroxide induced cell death in part by virtue of their antioxidant enzymes; aqueous extracts have dose dependent cholinergic activity thereby improving memory performance (according to P.L.Rajagopal.et al,). Organic methanolic fraction of seed extract exhibited Anticholinesterase activity and cholinesterase inhibitory effect this was found to be significant with respect to IC50 values (according to Shashank. D et. al,).

\section{Acorus calamus: $10,54-58$}

It is a perennial herbaceous monocot wetland plant native to India, Europe, Japan, and China, posses rejuvenating property hence used in Ayurvedic system of medicine. Broadly fatty acids, essential oils, sugars are the Phytochemicals in the rhizomes of the plant such as $\alpha, \beta$ Asarone, Cis and trans isoeugenol these are identified using paper chromatography confirmed by direct comparing with authentic samples. Extracts of this plant are used to treat fever, cough, disorders related to digestion. Degradation of Acetyl cholinesterase in the synapses can inhibit with the aid of active constituents in it and also used for the treatment of memory related disorders.

\section{Matricaria chamomilla: $10,59-65$}

It is a annual herb grows as weed in low lying areas of India, North and South America, Australia. Terpinoids like $\alpha$-Bisbolol, $\alpha$-Bisbolol oxide A and B, Sesqueterpenes, Luteolin, Coumarins, Umbelliferone and polysaccharides are the chemical constituents in the plant. Phytoconstituents of this plant extracts are responsible for Neuroprotective and Anti-oxidant activity; it is the chief rationale for using this plant as herbal medicine for $\mathrm{AD}$.

\section{Galanthus Nivalis: $66-69$}

A perennial herb that germinates from blubs widely cultivated in Europe and native to large areas of Spain, Ukraine and France. Glantamine is the main Active Phytochemical in it along with it Lectin or agglutinin and alkaloids (Tazettine, Pretazettine) are also present. It is a low protein bound drug showing large volume of distribution. Glantamine amplifies the effects of Ach by activating Nicotine receptors which are responsible for learning and memory; it also elevates the levels of Glutamine, GABA and Seratoine due to its allosteric modulator activity. It can be used as cognitive enhancer as it efficiently reverses the cognitive deficits in rat models.

\section{Tinospora cordifolia: $10,70,71$}

It is a perennial herbaceous plant native to India, Myanmar and Srilanka, warm climate along with red or black soil are more preferable for the growth of the plant. Seeds and vegetative cuttings are methods of propagation. Phytoconstituents of the plant are Steroids, Alkaloids, Polysaccharides, and Glycosides. It helps in stimulation of Immune system and memory and Anti-oxidant activity makes the plant useful as a medicinal herb to treat AD.

\section{Rosmarinus officinalis: $4-6,10,72-77$}

This plant is commonly called as rosemary native to North Africa and Spain used as culinary condiment and also in perfume preparations. It is a good source of Vitamin B-6, iron, calcium. Monoterpenes (pinene, camphene, myrcene, limonine), Monoterpenols (broneol) are the chemical constituents. Essential oil extracted from this plant contain 1, 8-Cineole hence used in Aromatherapy, it stimulated body and brain, Improves cognitive performance in terms of speed and accuracy. Researchers have revealed that certain Phytochemicals in the herb put a stop to the degradation of acetylcholine, an important brain chemical needed for normal neurotransmission. A shortage of this chemical is normally seen in Alzheimer's patients.

\section{Morinda citrifolia: ${ }^{79-83}$}

It is a tree that belongs to Coffee family widely cultivated across Asia, Australia, and each part of the tree has medicinal value. Earlier in Polynesian and traditional culture they were used as a Tonic and famine food, few regulatory agencies approved skincare products prepared from it, chemical constituents include Alkaloids, Lignans, Oligo and polysaccharides, flavanoids, additional it's a plant with high nutrition value it contains carbohydrates, dietary fibers, vitamin A, B3, C, Iron, potassium. When animals are administered with Noni juice there was a marked difference in free radical scavenging activity, Anticancer, Anti-inflammatory, Oxidation of LDL, are being reported, Anti-oxidant value of the extract varies depending upon the age of part taken, it also inhibits the metabolism of Acetyl choline by interfering with the action of Acetylcholine esterase.

\section{Grape seeds Extracts: $5,84-92$}

It is a deciduous woody flowering plant in North east countries it is widely cultivated. Consumed a table grape or transformed into wine, jam, jelly, extracts, seed oils, raisins. Fruits from these plants are of different colors which include green, pink, orange, yellow, dark purple, black. Variations of purple color in red wine are due to the quantity of Anthocyanins and others polyphenolic pigments. Grape polyphenols may heighten cognition and guard your noggin by maintaining vascular health and function additionally they play important role in signaling neurotransmitters and reducing your risk of risky oxidation, both linked to a lower risk of cognitive decline as a part of a plant-based diet.

\section{Melissa officinalis: $4,5,10,11$}

It is a perennial herb of mint family native to south central Europe, Central Asia, and America with culinary and medicinal uses. Chemical constituents of this plant are Eugenol, Citral A and B, Tannis, Terpenes, Citronellal, Traces of Harmine, Rosemaric acid. The leaves of this plant contain Monoterpenes (ex-citral) with weak anti-acetyl cholinesterase activity and phenol carboxylic acids which 
shows Anti-oxidant and Anti-Amyloid and Anti-apoptotic effects this plant has central nervous system receptor activity and modulates mood cognitive performance following acute administration.

\section{Utrica dioica: $11,93,94$}

It is a vetinary folk medicine and perennial herb generally grown as a woody plant and generally grown as a weed plant in agriculture. This herb has medicinal uses in combination and alone it is used to treat many disease or problems related to infertility, lactation, management of internal organs functioning. The chemical constituents of this are Lignans, isolecthins, Terpenes, proteins, vitamins, minerals, flavanoids, and tannins. Methanolic extract of this plant with a dose of $0.5 \mathrm{~g} / \mathrm{kg}$ for 30 days is used for the growth of ornamental fish and has immunosimulatory activity. Along with regular exercise and this plant extract there is chance of reduction in brain lesions in rats.

\section{Salvia officinalis: 95}

It is a perennial flowering subherb native to meditarian region and also in many places throughout the world, grows in all types of soil; this herb was reported to be a multipurpose herb with medicinal, traditional, ornamental and culinary use. The Phytochemicals in the plant makes it more special in treating various problems related to infertility, diuretics, and local anaesthetic for skin, styptic, anti-oxidant. These constituents include 1,8cineole,

\section{REFERENCES}

1. Anne Waug, Allison Grant. Ross and Wilson. Anatomy and Physiology in Health and Illness. 9th Edition. Churchill Livingstone. 2004.

2. Rang HP, Dale MM, Ritter JM, Flower RJ. Rang and Dale's Pharmacology. $6^{\text {th }}$ Edition.

3. Dennis Seow, MBBS, MRCP, FAMS (Geriatric Medicine), Serge Gauthier, MD, FRCPC2, Pharmacotherapy of Alzheimer Disease. The Canadian Journal of Psychiatry 2007; 52(10):620-629.

4. John Schmid. Aromatherapy for Alzheimer's and Dementia Good Alternative Therapy. 2018, 1-14.

5. Benjamin Pearce, Aromatherapy for Alzheimer's. 2013; 1-14.

6. Jimbo D , Kimura Y, Taniguchi M, Inoue M, Urakami K. Effect of aromatherapy on patients with Alzheimer's disease. PubMed - NCBI, 2009; 9(4):173-9.

7. Hannah Nichols. Alzheimer's disease: Music, meditation may improve early cognitive decline, January 2017, 1-4.

8. Khalsa DS. Stress, Meditation, and Alzheimer's Disease Prevention: Where The Evidence Stands. PubMed - NCBI, 2015; 48(1):1-12.

9. Jennifer d'angelo friedman. Benefits of Yoga and Meditation for Alzheimer's and Dementia, Yoga journal, 2015; 23:1-3.

10. Rajagopal PL, Ashlyjames, K.Premaletha P.N.Sajith kumar, Journal of International Academic research for Multidisciplinary. 2013; (9):1-14.

11. Agarwal P, Alok S, Fatima A, Singh PP. Herbal remedies for neurodegenerative disorder (Alzheimer's disease): A Review, IJPSR, 2013; 4(9):3328-3340.

12. https://www.nia.nih.gov/health/alzheimers

13. Finkel, Richard; Clark, Michelle A; Cubeddu, Luigi X. Lippincott's Illustrated Reviews: Pharmacology, 4th Edition. Lippincott Williams \& Wilkins. 2009.

14. Siegfried K. The cholinergic hypothesis of Alzheimer's disease, Central Clinical Research/Neuroscience, Hoechsl AG, anhjirt ( M ), Germany.

15. Bagad M, Khan Z, towards understanding Alzheimer's diseaseAn overview, Brain atrophy in advanced Alzheimer's disease https://www.researchgate.net/figure/Brain-Atrophy-inAdvanced-Alzheimers-Disease

16. Fisiopatología de la EA: Nuevos mecanismos, 2014. http://www.revneurol.com/sec/RSS/noticias.php?idNoticia= $\underline{4446}$ camphor, $\alpha$ and $\beta$ - thujone, vridiflorol, $\alpha$-pinene. To the patients in mild to moderate stage of AD a fixed dose of 60 drops/kg extract is administered for a period of 4 months results from the study stated that patients are free from agitation through out there life time. This extract also protects brain from oxidative damage to presences of Rosmarinic and carhosic acid in it.

\section{CONCLUSION}

Due to poor patient compliance towards drugs and their lethal side effects upon choric usage, at present there was a paradigm shift of patient choice of medication towards herbal which made a revolution this due to many advantages over the medications it has less adverse effects and they target the site easily upon slight modification its physicochemical properties, in spite of all these herbal therapy is economical to all classes of population. Even on any slight overdose of medicine will not be a problem. Out of all these advantageous aspects herbal medicine became a best choice of medication for management AD along with this regular meditation and yoga add more benefits for better and fast recovery of patient from AD.

Acknowledgement: I also extend my gratitude to Principal and Chalapathi Institute of Pharmaceutical sciences and funding agency AICTE-RPS Scheme sanctioned with file no: 8-76/RIFD/RPS/Policy-1-20162017 for the support.
17. Alistair burns, Robin jacoby, Raymond levy, Neurological Signs in Alzheimer's disease, Age and Ageing 1991; 20:45-5.

18. Tripathi KD. Essentials of Medical Pharmacology. $6^{\text {th }}$ Edition. Jaypee Brothers Medical Publishers (P) Ltd. 2009.

19. christiane Reitz, Alzheimer's disease and Amyloid cascade hypothesis- A critical overview, International journal of Alzheimer's disease, 2012, 1-11,

https://www.semanticscholar.org/paper/Alzheimer'sDisease-and-the-Amyloid-Cascade-A-Reitz

20. Amyloid $\beta$-protein and Synaptophysin https://medicalneurophys.wordpress.com/2012/08/29/amyl oid-\%CE\%B2-protein-and- synaptophysin/

21. Terry V,Buccafusco JJ, the Cholinergic Hypothesis of Age and Alzheimer's Disease-Related Cognitive Deficits: Recent Challenges and Their Implications for Novel Drug Development, Journal of Pharmacology and Experimental Therapeutics September 2003; 306(3):821-827.

22. Favade Aditya Shahaji*, Chavan Sadhana P, A Review on Alzheimer's disease and its concepts in ayurveda, International Journal of Ayurveda and Pharma Research, October 2015; 3(10):52-56.

23. Rao RV, Olivier Descamps, Varghese John1 and Dale E Bredesen, Ayurvedic medicinal plants for Alzheimer's disease: a review, Alzheimer's Research \& Therapy 2012; 1-9.

24. Singhal AK, Naithani V, Bangar OP, Medicinal plants with a potential to treat Alzheimer and associated symptoms, International Journal of Nutrition, Pharmacology, Neurological Diseases, May-August 2012; 2(2):84-91.

25. Dileepkumar K J Shreevathsa S, Bharathi Hiremath, Shivappa Pujari, Alzheimer's disease : An Ayurvedic Perspective, Jour. of Ayurveda \& Holistic Medicine, jan 2015; 2(9):1-6.

26. Singhal AK, Naithani V, Bangar OP. Medicinal plants with a potential to treat Alzheimer and associated symptoms.Int J Nutr Pharmacol Neurol Dis 2012; 2:84-91.

27. Shiksharthi AR et al., Journal of Pharmacy Research 2012; 5(4):1872-1881.

28. Hassan MAG, Rajkapoor Balasubramanian, Ali Daw Masoud, Zamzam Elmahdi Burkan, Abdussalam Sughir, Raju Senthil Kumar, Role of medicinal plants in neurodegenerative diseases with special emphasis to Alzheimer's disease, International Journal of Phytopharmacology. 2014; 5(6):454462 . 
29. Kaur J, Singh R, Singh G, Kaur H, Kaur J, Kaur M, Singh P, Kaur J, A Systematic Review on Huperzia serrata, International Journal of Pharmacognosy and Phytochemical Research 2016; 8(8):1250-1255.

30. Roy A, A Review on Medicinal Plants for Alzheimer's disease.SF J Herb Med, 2017; 1:2.

31. Dastmalachi K. Damien HJ, Dorman, Heikki Vuorela, Raimo, Hiltunen, Plants as potential source for Drug development against Alzheimer's Disease, International journal of Biomedical and pharmaceutical sciences, 2007; 83-104.

32. Roy A. Role of medicinal plants against Alzheimer's disease. Int J Complement Alt Med. 2018; 11(4):205-208.

33. John M. Ringman, Jeffrey L. Cummings, Sally A. Frautschy, Gregory M. Cole, Donna L. Masterman. A Potential Role of the Curry Spice Curcumin in Alzheimer's disease. Curr Alzheimer Res. 2005; 2(2):131-136.

34. Umadevi M, Rajeswari R, C. Sharmila Rahale, S. Selvavenkadesh, R.Pushpa, K.P.Sampath Kumar, Debjit Bhowmik, Traditional and medicinal uses of Withania somnifera, The pharma innovation, 2012; 1(9):102-109.

35. Gohil KJ, Jagruti A. Patel, A review on Bacopa monniera: Current research and future prospects, International Journal of Green Pharmacy, January-March 2010, 1-9.

36. Sundaramurthi $P$ and Packiam KK, A Review on Pharmacognosy and Pharmacology of Evolvulus alsinoides (1.) International Research Journal of Pharmacy, 2014; 1-4.

37. Lakshmi T, Roy A, Geetha R., Panax ginseng - A universal panacea in the herbal medicine with diverse pharmacological spectrum -A Review, Asian journal of pharmaceutical and clinical research, 2011; 4(1):14-18.

38. Sarup P, Bala S, Kamboj S, Pharmacology and Phytochemistry of Oleo-Gum Resin of Commiphora wightii (Guggulu), Hindaw Publishing Corporation Scientifica 2015; Article ID 138039, 14 pages.

39. Lise Alschuler, ND, FABNO, Magnolia officinalis: An Overview of the Research and Clinical Indications, Plant intelligence and Professional Resource.

40. Gray, Nora.et.al., Caffeoylquinic Acids in Centella asiatic a Protect against Amyloid- $\beta$ Toxicity, , Journal of Alzheimer's disease, 2014; 40(2):359-373.

41. Centella Asiatica (Gotu Kola) \& Your Brain | Cognitive Vitality Alzheimer's Drug Discovery Foundation, 2018, 1-6.

42. Haeun Kim, Jin Tae Hong, Mi Hee Park*, Centella asiatica enhances neurogenesis and protects neuronal cells agains H202-induced oxidative injury, J Biomed Res 2015; 16(3):121 128.

43. Dhanasekaran M, Holcomb LA, Hitt AR, Tharakan B, Porter JW, Young KA, Manyam BV, Centella asiatica extract selectively decreases amyloid beta levels in hippocampus of Alzheimer's disease animal model. - PubMed - NCBI, 2009; 23(1):14-9.

44. Ma y a Caruso, BS; Nor a Gr a y, PhD; Don Don Matthews, PhD Christ opher Harris, BS; Kirsten W right, ND , MS; Amala Centella asiatica extract improves cognition in two mouse models of Alzheimer's disease, International Congress 2018, 13.

45. Hamidpour R, Hamidpour $\mathrm{S}$, Hamidpour $\mathrm{M}$, et al Medicinal Property of Gotu kola (Centella asiatica) from the Selection of Traditional Applications to the Novel Phytotherapy. Arch Cancer Res. 2015, 3: 4

46. Sunanda BPV, Latha K, Rammohan B, Uma Maheswari MS and Surapaneni Krishna Mohan, Evaluation of the Neuroprotective Effects of Centella asiatica Against Scopolamine Induced Cognitive Impairment in Mice, Indian Journal of Pharmaceutical Education and Research , 2014; 48(4):31-34.

47. Chiroma SM, Mohamad Aris Mohd Moklas, Che Norma M, Mohamad Taufik H, Zulkhairi Amon, Saravanan Jagadeesan, and Bulama Ibrahim, Neuro-therapeutic Benefits of Centella asiatica on Some Neurodegenerative Diseases: A Review, Research Journal of Pharmaceutical, Biological and Chemical Sciences, RJPBCS, 2017; 8(6):549-556.

48. Gohil KJ, Patel JA, Gajjar AK, Pharmacological Review on Centella asiatica: A Potential Herbal Cure all, Indian J Pharm Sci. 2010; 72(5):546-556.

49. Kamalinee A. Deodhar and Nanda W. Shinde, Celastrus paniculatus; medicinal and pharmacological properties: a review, International Journal of Development Research, 2015; 5(9):5526-5531
50. Jyotishmati Fruit Extract - Health Benefits, Nutrition, \& Uses for Jyotishmati Fruit Extract, 2018, 1-8.

51. Sharma S, Tilak AV, GLakhanpal, Manjare R, Rane BT, Sanjay Dabhade, Modulation of working memory by Mentat and Donepezil using ECT induced amnesia in rats, 2016; 593):1-9.

52. Bhanumathy M, Chandrasekar SB, Chandur U, Somasundaram T, Phyto-pharmacology of Celastrus paniculatus: An Overview, International Journal of Pharmaceutical Sciences and Drug Research 2010; 2(3):176-181.

53. Sharma P, Shrivastava NM and Shrivastava S, Role of "Jyotishmati"in the treatment of CNS disorders, International Conference on "Recent Advancement in Science \& Technology" (ICRAST 2017), 29-30.

54. Balakumbahan $\mathrm{R}$, Rajamani $\mathrm{K}$ and Kumanan $\mathrm{K}$, Acorus calamus: An overview, Journal of Medicinal Plants Research, 2010; 4(25):2740-2745, December Special Review.

55. Valay S, Ragavendra M., Sushma M., and V. Uma Maheswara Rao, Evaluation of Nootropic activty of Acorous calamus against scopolamine induced Alzheimer's, World Journal of Pharmacy and Pharmaceutical Sciences, 2015; 4(11):17431758

56. Vijayapandi et al., In vitro Anticholinergic and Antihistaminic activities of Acorus calamus linn. Leaves extracts, Afr J Tradit Complement Altern Med. 2013; 10(1):95-101.

57. Yende SR, Harle UN, Dajgure DT, Tuse TA and Vyawahare NS Pharmacological profile of Acorus calamus: An Overview, Pharmacognosy Reviews [Phcog Rev.], 2008; 2(4):22-26.

58. Imam H, Riaz Z, Azhar M, Sofi G, Hussain A. Sweet flag (Acorus calamus Linn.): An incredible medicinal herb. Int J Green Pharm 2013; 7:288-96.

59. Chamomile: Medicinal, Biochemical, and Agricultural Aspects, Introduction to Chamomile, $\mathrm{s}$

60. Singh O, Kahnam Z, Misra N, Manoj, Srivatsava K, Chamomile (Matricaria chamomilla L.): An overview, Pharmacogn Rev. 2011; 5(9):82-95.

61. Assessment report on Matricaria recutita L., flos and Matricaria recutita L., aetheroleum, European Medicines Agency, 2014, 2-62.

62. Asgharzade S, Radiei Z, Mahmoud, Rafieian Kopaei, Effect of Matricaria Chamomilla extract on motor coordination impairement induced by Scopalamine by Rats, Asian Pac J Trop Biomed 2015; 5(10):829-833.

63. Ranpariya VL , Parmar SK, Sheth NR, Chandrashekhar VM, Neuroprotective activity of Matricaria recutita against fluorideinduced stress in rats, Pharm Biol. 2011; 49(7):696701

64. Gupta V, Mittal P, Bansal P, Khokra SL, Kaushik D, Pharmacological Potential of Matricaria recutita-A Review, International Journal of Pharmaceutical Sciences and Drug Research 2010; 2(1):12-16.

65. Sayyar Z, Yazdinezhad A, Hassan M, and Iraj Jafari Anarkooli, Protective Effect of Matricaria chamomilla Ethanolic Extract on Hippocampal Neuron Damage in Rats Exposed to Formaldehyde, Volume 2018, Article ID 6414317, 1-10.

66. Jim English, Galantamine: Preserving Memory and Cognitive Function, By NutritonReview.org - April 22, 2013, 1-4

67. Michael Heinrich*, Hooi Lee Teoh, Galanthamine from snowdrop-the development of a modern drug against Alzheimer's disease from local Caucasian knowledge, Journal of Ethnopharmacology, 2004; 92:147-162.

68. S.V. Ley, R.M. Myers, Galanthus - an overview, Science Direct Topics, Comprehensive Medicinal Chemistry II, 2007, 1-10.

69. Treating Alzheimer's disease with Galantamine (RAZADYNE®) - Kindly Care, 2018, 1-11.

70. Madhav Mutalik, Mutalik Maitreyee, Tinospora Cordifolia: role in depression, cognition, memory, National Herbalists Association of Australia, 2011; 23(4):168-173.

71. Mittal M, Sharma MM, Batra A, Tinospora cordifolia: a multipurpose medicinal plant- A review, Journal of Medicinal Plants Studies, 2014,: 2(2):32-47.

72. Stasia Bliss, Alzheimer's - Rosemary Improves Memory.

73. Nancyg, rain-Boosting Rosemary Oil May Slow Alzheimer's Onset, Budibar, 2016; 1-3.

74. Joseph Nordqvist, Rosemary: Health benefits, precautions, and drug interactions, Medical News today, 201; 1-6.

75. Filiptsova O.V., et al.., The effects of essential oils of lavender oil and Rosemary on the human short-term memory, Alexandria Journal of Medicine, 2017; 1-4. 
76. Filiptsova OV et al. The essential oil of rosemary and its effect on the human image and numerical short-term memory. Egyp. Jour. Bas. App. Sci. 2017; 1-5.

77. Habtemariam S, The Therapeutic Potential of Rosemary (Rosmarinus officinalis) Diterpenes for Alzheimer's Disease, Evidence-Based Complementary and Alternative Medicine Volume 2016; Article ID 2680409, 1-14.

78. Samoylenko V, Zhao J, D. Chuck Dunbar, Ikhlas A. Khan, James W. Rushing, and Ilias Muhammad, New Constituents from Noni (Morinda citrifolia) Fruit Juice, J. Agric. Food Chem., 2006; 54(17):398-6402.

79. Praveen $\mathrm{K}$ and Yellamma K: Insilco Identification of Suitable Acetuylcholinesterase Inhibitors from Morinda Citrifolia Linn. With Reference To Alzheimer's disease. Int J Pharm Sci Res 2014; 5(12):5474-81.

80. Devaprasad M, Kumaran santhalingam, Subramaniyan kannaiyan, Sanmathi suresh3, Benedict paul, Virtual screening of Phytochemicals of Morinda citrifolia as Anti- inflammatory and Anti- alzheimer agents using molegro virtual docker on p38 $\alpha$ mitogen-activated protein kinase enzyme, Asian J Pharm Clin Res, 2015; 8(6):141-145.

81. Jian Yang*, Rama Gadi, and Talene Thomson, Antioxidant capacity, total phenols, and ascorbic acid content of noni (Morinda citrifolia) fruits and leaves at various stages of maturity, Micronesica. 2011; 41(2):167-176.

82. Jeyabalan S, Subramanian K, Cheekala UMR, Krishnan C. In vitro \& ex vivo Acetylcholinesterase Inhibitory Activity of Morinda citrifolia Linn (Noni) Fruit Extract. Pharmacog J. 2017; 9(6):900-5.

83. Steve frailey, Why Noni is So Special- Memory Loss, 2018, 1-8.

84. Giulio Maria, Pasinetti, and Lap Ho, Role of grape seed polyphenols in Alzheimer's disease neuropathology, Nutr Diet Suppl . 2010; 2010(2):97-103.

85. Heidi J. Wengreen, Ron Munger, Chris Corcoran1, Peter Zhandi, JoAnn Tschanz, Fruit and vegetable intake and cognitive function in the elderly: the cache county study on memory, health and aging, Non-pharmacological Treatments / 1 (Suppl 1) (2005), 100-101.

86. Souad El Gengaihi, Doha H Abou Baker, Grape Seeds Extract as Brain Food: A Review, International Journal of Pharmaceutical and Clinical Research 2017; 9(1):77-85.

87. Pasinetti GM et al., Development of grape seed phenolic extract with anti-oligomeric activity as a novel treatment in progressive supranulear plasy and tauopathies, Journal of neurochemistry, 2010; 114:1557-1568.

88. Wang, Y.J; Thomas, P.; Zhong, J.H.; Bi, F.F.; Kosaraju, S.; Pollard, A.; Fenech, M.; Zhou, X.F. Consumption of Grape Seed Extract Prevents Amyloid-beta Deposition and Attenuates Inflammation in Brain of an Alzheimer's Disease Mouse. Neurotoxicity Research. 2009; 15(1):3-14.

89. Stephen Daniells, Grape seed extract may prevent Alzheimer's: study, Nutra ingredients.com, 2008; 1-2.

90. Yan-Jiang Wang Æ Philip Thomas Æ Jin-Hua Zhong Æ FangFang Bi Æ Shantha Kosaraju Æ Anthony Pollard $Æ$ Michael Fenech $Æ$ Xin-Fu Zhou, Consumption of Grape Seed Extract Prevents Amyloid-b Deposition and Attenuates Inflammation in Brain of an Alzheimer's Disease Mouse, Neurotox Res 2009; 15:3-14.

91. Gionata De Vico, Vincenzo Guida, and Francesca Carella, Urtica dioica (Stinging Nettle): A Neglected Plant With Emerging Growth Promoter/ Immunostimulant Properties for Farmed Fish, Front Physiol. 2018; 9:285):1-5.

92. A. Toldy et al., The beneficial effects of nettle supplementation and exercise on brain lesions and memory in rats, Journal of Nutritional Biochemistry 2009; 20:974 -981.

93. Sepide Miraj and Sara Kiani, A review study of therapeutic effects of Salvia officinalis L, Scholars Research Library, 2016; 8(6):299-303. 